\title{
Polyphenols from Passiflora ligularis Regulate Inflammatory Markers and Weight Gain
}

https://doi.org/10.1515/bmc-2021-0005

received March 5, 2021; accepted April 14, 2021.

\begin{abstract}
Weight-related disorders affect more than half of the adult population worldwide; they are also concomitant with a state of chronic low-grade inflammation manifesting in abnormal cytokine production. The present study evaluated the effect of polyphenol and flavonoid extract from Passiflora ligularis (granadilla) on low-grade inflammation and body weight in overweight Wistar rats. To induce weight-gain, rats were fed a chow diet with $30 \%$ sucrose water and supplemented with 2.0, 2.5, and $3.0 \mathrm{~g} / \mathrm{L}$ polyphenol extracts $(n=16)$. The design was a $3+1$ factorial model performed for 42 days (granadilla polyphenols, 3 levels of supplementation, and 1 control group). In addition to total polyphenol and total flavonoid content, the major identified and quantified polyphenol, via UHPLC, was ferulic acid. Interleukin 6 (IL-6), and cytokine tumor necrosis factor-alpha (TNF- $\alpha$ ) were evaluated in serum. A decline in the concentration of TNF- $\alpha$ and in weight-gain was found in $P$. ligularis (granadilla) groups treated with the $2.5 \mathrm{~g} / \mathrm{L}$ dose. Consumption of polyphenol extracts from granadilla inhibits interleukin-activity as an indicator of inflammation and aids in body-weight control, considering similar food intake, in overweight Wistar rats.
\end{abstract}

Keywords: Passiflora ligularis (granadilla); phenolic compounds; anti-inflammatory activity; overweight rats.

\section{Introduction}

Adipose tissue functions as an energy reserve for the organism and as a secretory tissue capable of producing biologically active molecules, such as resistin, leptin,

\footnotetext{
*Corresponding author: Juan Carlos Carmona-Hernandez, Grupo de Investigacion Medica, Universidad de Manizales, Manizales, Colombia, E-mail: jucaca@umanizales.edu.co Jaime Angel-Isaza, William Narváez-Solarte, Clara Helena GonzalezCorrea, Research Group on Nutrition, Metabolism and Food Security, Universidad de Caldas, Manizales, Colombia
}

tumor necrosis factor alpha (TNF- $\alpha$ ) and interleukins (IL) [1]. These substances activate signalling pathways in the inflammation cascade, leading to macrophage infiltration in adipose tissue and M1 macrophage activation. Macrophages secrete pro-inflammatory cytokines IL-1 $\beta$, IL- 6 , and TNF- $\alpha$. Interaction between adipose tissue and the defensive cells aggravates and maintains a systemic inflammatory state from which low-grade chronic inflammation originates [2,3].

There is a growing interest in studying polyphenols to reduce negative effects related to chronic low-grade inflammation present in obesity. These compounds are secondary metabolites of plants that participate in biological processes such as growth, reproduction, and protection from external threats [4]. In animals, polyphenols from the leaves of Camellia sinensis (green tea) have shown a positive correlation between their consumption and lowered risk of metabolic disorders related to being overweight [4,5]. Other plants with significant amounts of polyphenols could display similar effects.

Polyphenols such as flavonoids, anthocyanins, and tannins are found in fruits of the Passiflora family, including Passiflora edulis (maracuyá) and Passiflora ligularis (granadilla) [6]. These fruits are cultivated in tropical South American countries and are normally consumed as peeled fruit or in fresh juice form. In Colombia, granadilla is of great economic importance, with an average annual production of 9.3 tons per hectare planted [7]. Thus, Passiflora is a potential source of polyphenols with benefits for both animal and human health $[6,8,9]$. The objective of this research is to evaluate the in vivo effects of polyphenol extracts from granadilla on low-grade chronic inflammation in overweight rats. We hypothesized that treatment with different concentrations of polyphenol extract from the fresh pulp and seeds of granadilla could be effective at reducing weight gain or inhibiting inflammatory markers in Wistar rats. 


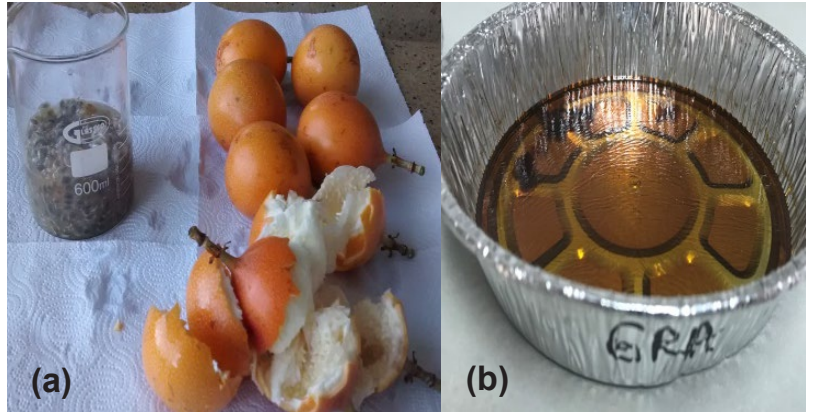

Figure 1: Passiflora ligularis (granadilla). (a) Fresh Colombian granadilla. (b) Granadilla (pulp and seeds) acetone $70 \%$ polyphenol-extract.

\section{Materials and Methods}

\section{Fruit, chemical reactants, and standard reference solutions}

Fresh granadilla, a total of $10 \mathrm{~kg}$, was purchased in a local market (Manizales - Colombia). Acetone, sodium carbonate, and Folin-Ciocalteu reagent were purchased from PanReac AppliChem, ITW Reagents, (Darmstadt Germany); acetonitrile, ammonium formate, formic acid, methanol, sodium dodecyl sulphate, and hydrated sodium taurocholate were purchased from Sigma Aldrich (St.Louis, MO - USA). Sodium nitrite and aluminium chloride were obtained from LOBA Chemie (Mumbai - India), and sodium hydroxide was obtained from EMSURE Merck (Darmstadt - Germany). UHPLC reference standards apigenin, cafeic acid, caffeine, carnosic acid, $( \pm)$-catechin, cyanidin, cyanidin-3-rutinoside, (-)-epicatechin, (-)-epicathechin gallate, (-)-epigallocatechin, (-)-epigalocathechin gallate, ferulic acid, kaempferol, kaempferol 3-glucoside, luteolin, naringenin, p-coumaric acid, pelargonidin, pelargonidin-3-glucoside, pinocembrine, quercetin, quercetin 3-glucoside, kaempferol 3-glucoside, rosmarinic acid, teofiline, theobromine, ursolic acid, and vanillic acid were acquired from Sigma Aldrich (St. Louis, MO - USA). Human tumor necrosis factor alpha (TNF- $\alpha$ ) and interleukin - 6 (IL-6) kits were obtained from BioLegend (San Diego, CA - USA).

\section{Polyphenol extraction and quantification}

Based on national agricultural industrial standards for Passifloras, granadilla at degree 5 of ripening were selected by simple random sampling by conglomerates, with a variability of $10 \%$ in size, shape, and maturing state [10]. The fruits were washed in sodium hypochlorite (50 ppm) and dried with absorbent paper [11]. The pulp and seeds were homogenized in a commercial blender (Oster® XpertSerier ${ }^{\mathrm{TM}}$ - USA). The mixture was kept at $4^{\circ} \mathrm{C}$ prior to the extraction process [12].

The homogeneous mixture, in equal volumes, was placed in $70 \%$ acetone, stirred for 20 minutes at 500 rpm (Dragon Lab MS-H Pro ${ }^{\circledR}$ - China), sonicated for 15 minutes (Branson ${ }^{\circledR}$ MH ${ }^{\mathrm{T} M} \bmod 3800$ series - USA), and centrifuged at $3500 \mathrm{rpm}$ for 15 minutes (Hermle ${ }^{\circledR} \mathrm{Z} 206$ A). The solvent was rotaevaporated (Scilogex ${ }^{\circledR}$ RE 100 pro - USA), and the polyphenol-rich extract was dehydrated at $50{ }^{\circ} \mathrm{C}$ for 96 hours (Incucell ${ }^{\circledR}$ LSIS-S - Germany). Total phenolic content (TPC) was determined in triplicate according to the Folin-Ciocalteu reaction [11]. Samples of $0.50 \mathrm{~g}$ of dehydrated granadilla polyphenol-extracts were dissolved in $10 \mathrm{~mL}$ of distilled water. From this dilution, volumes of $0.50 \mathrm{~mL}$ were mixed with $0.50 \mathrm{~mL}$ of distilled water, $1.0 \mathrm{~mL}$ of Folin-Ciocalteu reagent with mixing for one minute, and with $2.0 \mathrm{~mL}$ of $3.5 \%$ sodium carbonate. The solutions were kept in the dark for 90 minutes at room temperature. The samples were read in a range of 620 to $800 \mathrm{~nm}$ (UV/VIS Optizen POP $\left.{ }^{\circledR}\right)$. The total polyphenol content was reported as gallic acid equivalents per $100 \mathrm{~g}$ of dehydrated extract (mg GAE/100 g DE).

\section{Total flavonoid content (TFC)}

Flavonoids within the largest polyphenol content were quantified via aluminium chloride $\left(\mathrm{AlCl}_{3}\right)$ colorimetric assay with modifications [13]. Volumes of $0.5 \mathrm{~mL}$ of extract, in triplicate, were placed in test tubes containing $2.0 \mathrm{~mL}$ of distilled water. To each solution, $150 \mu \mathrm{L}$ sodium nitrite $(5 \%)$ was added, followed by a 5 -second vortex. After 5 minutes, $150 \mu \mathrm{L} \mathrm{AlCl}_{3}$ (10\%) was added under the same agitation and reaction conditions. One $\mathrm{mL}$ of sodium hydroxide (1M) and $1.2 \mathrm{~mL}$ of distilled water were added for a total volume of $5 \mathrm{~mL}$, then vortexed and incubated for a final reaction time of 5 minutes [13]. TFC was quantified as milligrams of quercetin equivalents (QE) per 100 grams of fresh fruit (mg QE/ $100 \mathrm{~g}$ of fresh granadilla-approximate content in one unit of fresh fruit).

\section{UHPLC-MS analysis of phenolic compounds}

Dehydrated samples of granadilla extracts were dissolved in $70 \%$ methanol $(0.2 \%$ formic acid), vortexed, and sonicated for $5 \mathrm{~min}$ prior to chromatographic assays. 
All peak separation and chromatographic analysis of Passiflora extract was performed using a UHPLC Dionex Ultimate 3000 (Thermo Scientific, Sunnyvale, CA - USA) equipped with binary pump (HP G3400RS). Polyphenol content was separated with the aid of a Hypersil GOLD Aq (ThermoScientific, Sunnyvale, CA - USA) $100 \times 2.1 \mathrm{~mm}$, $1.9 \mu \mathrm{m}$ column at $30^{\circ} \mathrm{C}$. The mobile phase A contained aqueous ammonium formate $(0.2 \%)$ and B contained acetonitrile with ammonium formate (0.2\%). The initial gradient was set at $100 \% \mathrm{~A}$, switching linearly to $100 \%$ B over $8 \mathrm{~min}$ before being held at 100\% B for $4 \mathrm{~min}$, then returning to $100 \% \mathrm{~A}$ for $1 \mathrm{~min}$. The total running time was 13 minutes followed by three-minute post-runs [8].

A mass spectrophotometer Exactive Plus Orbitrap (Thermo Scientific, Sunnyvale, CA - USA) was connected to an electrospray ion source (ESI) and operated in positive mode with a voltage of $4.5 \mathrm{kV}$. Spectra were recorded in the range of $\mathrm{m} / z$ 60-900 for full scan MS analysis with nitrogen as the nebulizing gas. The Orbitrap MS detector was calibrated with certified reference solutions Ultramark ${ }^{\mathrm{TM}} 1621$ Mass Spec Std (ABCR GmBH \& Co., Karlsruhe - Germany), sodium dodecyl sulphate and hydrated sodium taurocholate (Sigma Aldrich, St. Louis, MO - USA). For polyphenol compound identification, a full-scan acquisition and ion extraction chromatogram (EIC) mode corresponding to $[\mathrm{M}+\mathrm{H}]^{+}$of polyphenols of interest was used. Mass measurements were calculated exactly and with a precision of $\Delta \mathrm{ppm}<0.001$ using a mixed solution of external phenolic standards, based on comparing calibration curves (concentration range from 0.05 to $5.00 \mu \mathrm{g} / \mathrm{mL}$ ).

\section{Animals, Overweight induction and treatments}

Sixteen adult male Wistar rats, (at least 120 days old) obtained from the same Institutional Bioterium and with an average initial weight of $288 \pm 25$ g, were kept under standard housing conditions (between 18 and $25^{\circ} \mathrm{C}$ and $50 \%$ relative humidity and 12 hours of daylight) in 800 $\mathrm{cm}^{2}$ plastic boxes covered with $5 \mathrm{~cm}$ thick rice husk for a period of 42 days.

The 42-day experimental period consisted of a 2-week adaptation period and a 4-week supplementation period for the corresponding intervention. Prior to the polyphenol interventions, the animals ( $n=4$ in each group) were induced to become overweight by being provided a chow diet $(28 \%$ crude protein, $12 \%$ fat, $3 \%$ fibre, $10 \%$ ash and $10 \%$ moisture) and 30\% sucrose water for the first two weeks [14]. The rats were weighed (from an initial mean weight of $280 \pm 2 \mathrm{~g}$ ) with an average weight-gain of 305 $\pm 2 \mathrm{~g}$. The treatments were distributed in a 3+1 factorial model (one source of polyphenol extracts from Colombian granadilla at concentrations of $2.0,2.5$, and $3.0 \mathrm{~g} / \mathrm{L}$ in drinking water, and one control group with no granadillapolyphenol supplementation, $n=4$ in each group). The animals were euthanized following the recommendations for the care and use of laboratory animals of the National Research Council (2001) [15]. This investigation focused on evaluating initial blood biomarkers associated with a direct effect on weight gain by comparing the polyphenol extracts at different concentrations. Future studies using supplements based on granadilla should evaluate other parameters related to inflammation or macrophage activation in tissues.

Ethical approval: The research related to animals' use has been complied with all the relevant national regulations and institutional policies for the care and use of animals. All experiments with animals were done at the Bioterium of Universidad de Caldas in Manizales (Colombia) with the approval of the Ethics Committee for Experimentation with Animals of the Faculty of Agricultural Sciences of Universidad de Caldas (protocol approved and signed February 20, 2018).

\section{Blood sampling and quantification of cytokines}

A $2.0 \mathrm{~mL}$ blood sample was collected from each rat to determine IL- 6 and TNF- $\alpha$ concentrations. Serum was obtained by centrifugation at $4500 \mathrm{rpm}$ for 5 minutes (Hettich ${ }^{\circledR}$ EBA 200 - Germany). Quantification of IL- 6 and TNF- $\alpha$ was performed via the enzyme-linked immunosorbent assay (ELISA) technique using the RAT IL-6 and RAT TNF- $\alpha$ kits. Plates were read in a Multiskan ${ }^{\mathrm{TM}}$ reader (Thermofisher ${ }^{\circledR}$ - USA). Blood samples in a microtainer with anticoagulant EDTA were used for all interleukin evaluations.

\section{Statistical analysis}

Results were tested for analysis of variance (ANOVA), and for those variables with a significant statistical difference $(p \leq 0.05)$, means were compared by Duncan or Tukey tests. The statistical program STATA $12 ®$ was used for all statistical evaluation. 


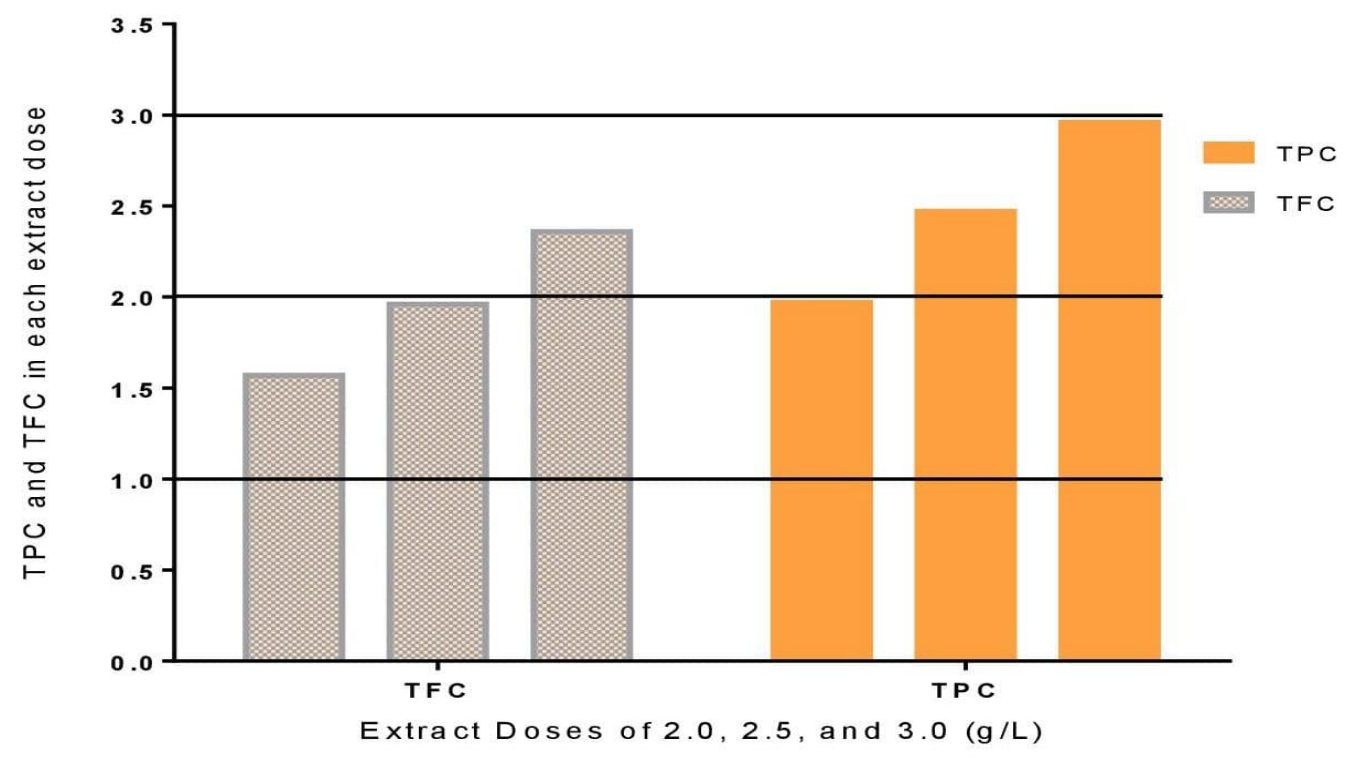

Figure 2: TPC and TFC in P. ligularis (granadilla) extract doses in drinking water.

\section{Results}

\section{Total Polyphenol Content (TPC) and Total Flavonoid Content (TFC) in pulp and seeds of P. ligularis (granadilla) Extract}

Polyphenol acetone (70\%) extract from fresh pulp and seeds of Colombian granadilla yielded a mean TPC of $986.02 \pm 6.17 \mathrm{mg}$ GAE in $100 \mathrm{~g}$ of fresh fruit. The equivalence in phenolic content with respect to each diluted dose (2.0, 2.5., and $3.0 \mathrm{~g} / \mathrm{L}$ ) in $100 \mathrm{~g}$ of fresh fruit corresponded to $1.97,2.47$, and $2.96 \mathrm{mg}$ GAE respectively. TFC values in terms of quercetin equivalents (QE) were $785.85 \pm 22.29$ $\mathrm{mg}$ QE in $100 \mathrm{~g}$ of fresh granadilla corresponding to diluted doses of 1.57, 1.96, and 2.36 mg QE in $100 \mathrm{~g}$ of fresh fruit. Figure 2 shows comparative levels of polyphenol and flavonoid quantitation for the three different doses corresponding to the three treatments (drinking water) for Wistar rats. The polyphenol and flavonoid proportions of the different doses registered their highest value of near $80 \%$ flavonoids in the highest treatment dose $(3.0 \mathrm{~g} / \mathrm{L})$.

\section{UHPLC-MS analysis of $P$. ligularis (granadilla) extracts}

Colombian granadilla polyphenols were identified by UHPLC-MS in electrospray ionization mode through comparison to several reference standards. Targeted quantification was used to characterize the phytochemical profiles of extracts from $P$. ligularis (granadilla). Sixteen polyphenol compounds were detected and quantified as shown in Table 1.

Concentrations of phytochemicals in the fruit extracts were determined for compounds detected above the LOQ $(0.05 \mu \mathrm{g} / \mathrm{mL})$ (Table 2). The main components detected were phenolic acids (with ferulic acid being the major quantifiable compound), a hydroxycinnamic acid, and several flavonoids. Representative chromatograms in Figure 3 illustrate peaks, retention times, and $\mathrm{m} / \mathrm{z}$ values for ferulic acid, the most concentrated phenolic compound identified in granadilla. Other predominant compounds detected in granadilla extracts were caffeine, luteolin, apigenin, ursolic acid, quercetin 3-glucoside, and pelargonidin.

\section{Weight gain and food intake}

After a 14-day adaptation period, supplementation with polyphenol extracts lasted 28 days (termed the "intervention period"). Table 2 provides the dose equivalence in $\mathrm{mg}$ of polyphenols per $\mathrm{kg}$ of body weight (BW) per day for the supplemented rats (drinking water with polyphenols), considering a mean extract volume of $1273.5 \mathrm{~mL}$ throughout the treatment. 
Table 1: Standard reference compounds, with their retention time and mass spectrum MS responses and concentrations for polyphenols in $P$. ligularis (granadilla) extract.

\begin{tabular}{llll}
\hline Reference Standards & $\begin{array}{l}\text { Retention Time } \\
(\mathrm{min})\end{array}$ & $\begin{array}{l}{[\mathrm{M}+\mathrm{H}]^{+}} \\
(\mathrm{m} / \mathrm{z})\end{array}$ & $\begin{array}{l}\text { P. ligularis (granadilla) } \\
\mu \mathrm{g} / \mathrm{mL}\end{array}$ \\
\hline theobromine & 3.63 & 181.07109 & $\leq 0.02$ \\
epigallocatechin & 3.80 & 307.07966 & $\leq 0.02$ \\
cyanidin 3-rutinoside & 3.90 & 595.16072 & $\leq 0.02$ \\
(+)-catechin & 3.97 & 291.08484 & $\leq 0.02$ \\
caffeine & 4.09 & 195.08672 & $0.02-0.05$ \\
(-)-epicatechin & 4.13 & 291.08776 & $\leq 0.02$ \\
epigallocatechin gallate & 4.15 & 459.08990 & $\leq 0.02$ \\
quercetin 3-glucoside & 4.45 & 465.09987 & $0.02-0.05$ \\
cyanidin & 4.55 & 287.05416 & $\leq 0.02$ \\
-coumaric acid & 4.63 & 165.05377 & $\leq 0.02$ \\
ferulic acid & 4.71 & 195.06422 & 0.94 \\
rosmarinic acid & 4.78 & 361.08999 & $\leq 0.02$ \\
pelargonidin & 4.82 & 271.05928 & $0.02-0.05$ \\
luteolin & 5.24 & 287.05356 & $0.02-0.05$ \\
apigenin & 5.53 & 271.05874 & $0.02-0.05$ \\
ursolic acid & 9.46 & 457.36631 & $0.02-0.05$ \\
\hline
\end{tabular}

Data are concentrations for extracted compounds from pulp and seeds of granadilla. LOQ (limit of quantification, based on a calibration curve ranging from 0.05 to $5.00 \mu \mathrm{g} / \mathrm{mL}$ ).

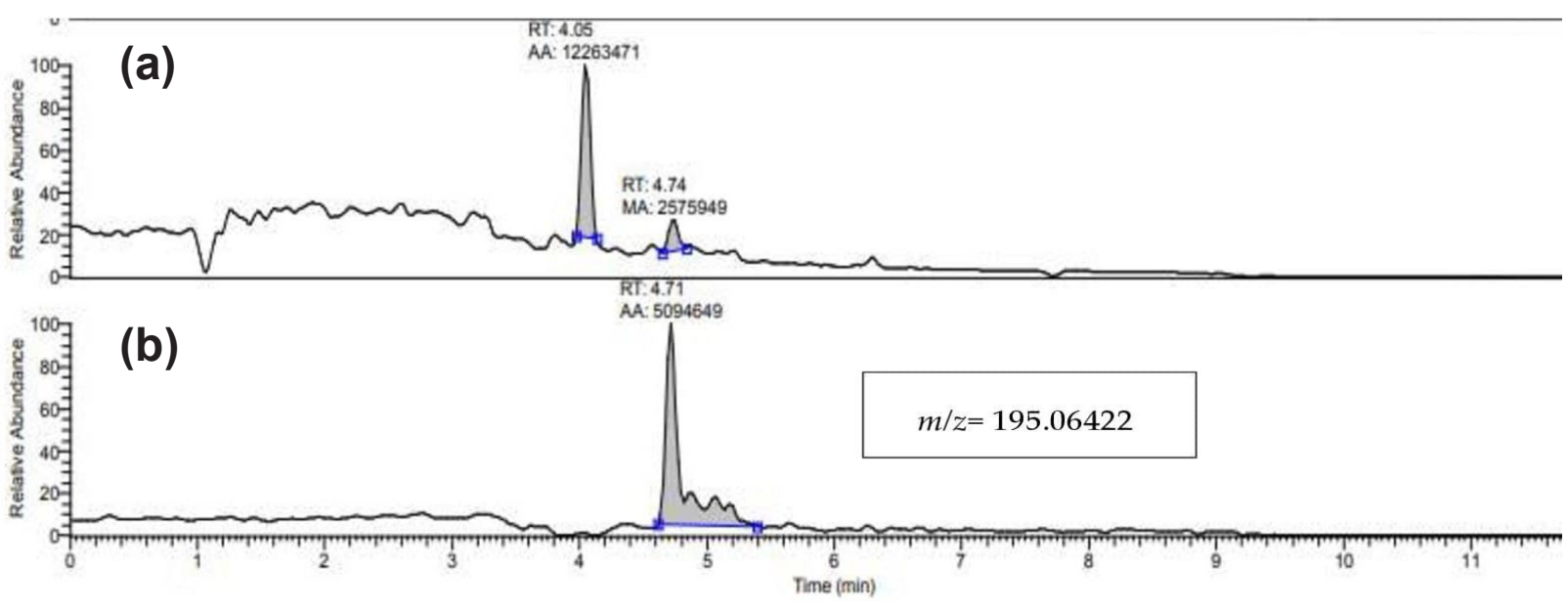

Figure 3: Total Ion Chromatograms (TIC) for extract of dehydrated pulp and seeds of granadilla in $70 \%$ acetone and its main comparative standard, ferulic acid. (a) Granadilla extract. (b) Ferulic acid, reference standard. 
(a)

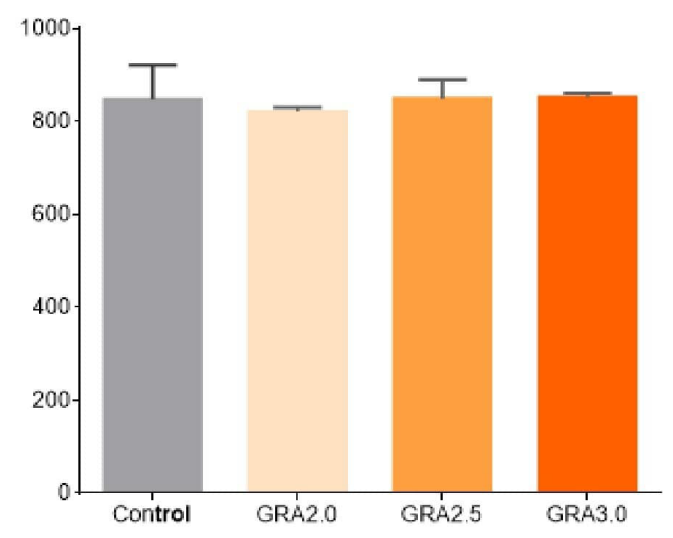

(b)

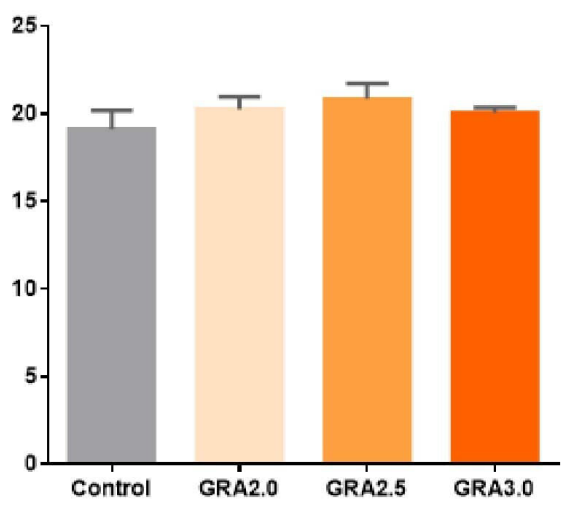

Figure 4: Data are means \pm standard deviation (S.D.) based on one-way ANOVA followed by Tukey test ( $n=4)$. No significant differences were detected $(p \leq 0.05)$. (a) Average food consumption for the duration of the study ( 42 days). (b) Daily average grams of food intake per animal. GRA: Granadilla at doses of 2.0, 2.5 and $3.0 \mathrm{~g} / \mathrm{L}$. No significant differences were detected for food consumption.

Table 2: Polyphenol-supplementation per kilogram of body weight per day and equivalence to a daily dose for a 60-kg human adult.

\begin{tabular}{|c|c|c|c|}
\hline \multirow[t]{2}{*}{ Dose of Extract (g/L) } & 2.0 & 2.5 & 3.0 \\
\hline & \multicolumn{3}{|c|}{ mg/kgBW/day } \\
\hline Polyphenol content/dose & 1.97 & 2.47 & 2.96 \\
\hline Polyphenol human dose & 1183.23 & 1479.03 & 1774.84 \\
\hline Number of fresh fruits & 1.20 & 1.50 & 1.80 \\
\hline
\end{tabular}

Data correspond to TPC (mg) in each dose and daily average volume of extract consumed by each animal during the intervention period (28 days). Data also represent TPC values for comparative daily intake of fresh granadilla for a human adult.

Average weight at the initiation of the supplementation was $350 \mathrm{~g}$. At the end of the diet adaptation period (14 days), body weight increased $17.7 \%$. The animals received food ad libitum, which contained $28 \%$ crude protein, $12 \%$ fat, $3 \%$ fibre, $10 \%$, ash, and $10 \%$ moisture, satisfying the nutritional requirements for Wistar rats, along with 30\% sucrose water to induce weight gain [16]. Water containing 2.0, 2.5, and 3.0 g/L polyphenol-rich extract was offered at will during the supplementation period of 28 days. Figure 4 represents food consumption during the study.

A significant statistical difference in weight (Figure 5) with respect to the control group was observed $(p=0.02)$. Treatments with all granadilla extracts yielded significant differences with respect to the non-supplemented group, considering no significant differences in food intake.

\section{Tumor necrosis factor alpha (TNF- $\alpha$ )}

Serum TNF- $\alpha$ was statistically reduced in animals supplemented with $2.5 \mathrm{~g} / \mathrm{L}$ of polyphenols from $P$. ligularis (granadilla) compared to both the lower-dose and control groups ( $p=0.03$ ) (Table 3). For animals treated with granadilla polyphenol-extracts at a concentration of $2.5 \mathrm{~g} / \mathrm{L}$ ( $1.75 \mathrm{mg} / \mathrm{kgBW} /$ day), TNF- $\alpha$ concentration was lowered more than $2 \%$.

\section{Interleukin 6 (IL-6)}

The concentration of serum IL-6 was not different between different doses of polyphenol extract, nor did it show a statistically significant effect relative to the control group. The highest IL- 6 decrease was registered at over $6 \%$ in rats treated with P. ligularis (granadilla) extracts with a TPC of $2.96 \mathrm{mg}$ per $\mathrm{kg}$ of body weight, highlighting a flavonoid proportion of $79.9 \%$.

\section{Discussion}

\section{Total polyphenol content in P. ligularis (granadilla)}

The TPC of $P$. ligularis (granadilla) in this study agrees with research in which TPC was quantified in different 


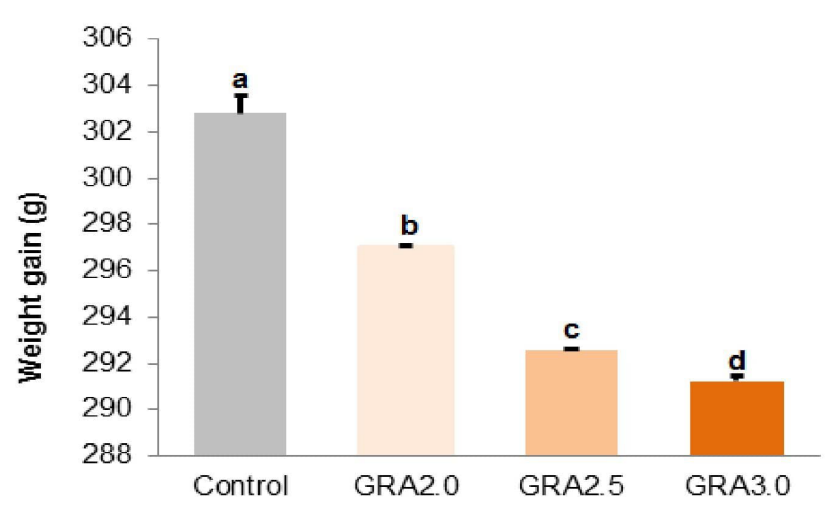

Figure 5: Animal weight at the end of the 42-day study. Data are presented as means \pm standard deviation (S.D.) for average weight in treated (GRA:Granadilla doses of 2.0; 2.5 and $3.0 \mathrm{~g} / \mathrm{L}$ ) and nontreated animals (control) based on one-way ANOVA followed by Tukey test $(n=4)$. Lower-case letters represent significant differences in treatments $(p \leq 0.05)$.

Table 3: Inflammatory markers in overweight Wistar rats after 42-day treatment.

\begin{tabular}{lllll}
\hline \multicolumn{5}{c}{ Extract dose in drinking water $(\mathrm{g} / \mathrm{L})$} \\
\hline & $\mathbf{0 . 0}$ & $\mathbf{2 . 0}$ & $\mathbf{2 . 5}$ & $\mathbf{3 . 0}$ \\
\hline $\begin{array}{l}\mathrm{TNF}-\alpha \\
(\mathrm{pg} / \mathrm{mL})\end{array}$ & $78.4 \pm 1.6^{\mathrm{a}}$ & $79.0 \pm 2.1^{\mathrm{a}}$ & $76.7 \pm 0.8^{\mathrm{b}}$ & $77.6 \pm 1.4^{\mathrm{ab}}$ \\
$\mathrm{IL}-6$ & $172.6 \pm$ & $169.1 \pm$ & $169.7 \pm$ & $161.9 \pm 5.7$ \\
$(\mathrm{pg} / \mathrm{mL})$ & 31.3 & 11.9 & 15.4 & \\
\hline
\end{tabular}

Data are means $+/-$ SD $(n=4)$. ab: Different letters for statistically significant differences $(p<0.05)$ based on one-way ANOVA followed by Duncan test.

Ecuadorian fruits; this study found $P$. ligularis to contain $91 \mathrm{mg}$ GAE per $100 \mathrm{~g}$ of fresh fruit, equivalent to a range of 325 to $455 \mathrm{mg}$ GAE per $100 \mathrm{~g}$ of dehydrated Colombian granadilla, depending on humidity [17]. These authors classified granadilla as a fruit with low phenolic content. On the contrary, in an experiment with 24 Colombian fruits, P. ligularis was classified as a fruit with a high TPC17, with one study reporting $664.8 \mathrm{mg}$ GAE per $100 \mathrm{~g}$ of fruit in freeze-dried powder and another showing $637.7 \mathrm{mg} \mathrm{GAE}$ per $100 \mathrm{~g}$ of dry matter (results in the present study are all reported per $100 \mathrm{~g}$ of fresh fruit) [18]. The polyphenol doses used in the present study $(2.0,2.5$, and $3.0 \mathrm{~g} / \mathrm{L})$ correspond respectively to $1.6,2.0$, and $2.4 \mathrm{mg}$ per $\mathrm{kg}$ of body mass per day in each animal, based on a dissolved polyphenol-rich extract consumption of less than 1300 $\mathrm{mL}$ throughout the intervention.
With respect to comparable human doses of fresh fruit for this particular type of Passiflora and considering three treatments with $2.0,2.5$, and $3.0 \mathrm{~g} / \mathrm{L}$ polyphenol extracts, equivalent supplementation of TPC content corresponds to approximately 1183, 1479, and $1774 \mathrm{mg} /$ $\mathrm{kg} /$ day, respectively, for a $60 \mathrm{~kg}$ adult. These values correspond to the content found in less than two fresh Colombian granadillas. The polyphenol and flavonoid content of these doses of fresh fruit are nutritionally relevant to human consumption. However, to the best of our knowledge, there are no previous studies reporting TPC and TFC for the edible parts (pulp and seeds) of fresh P. ligularis (granadilla).

TPC and TFCin plants are dependent on several factors. Genetic variety is important in polyphenol concentration, as are environmental and agronomic conditions, exposure to sunlight, degree of fruit maturation and type of crop [17]. Studies affirm that polyphenols and specific flavonoids participate in the response of the plant to environmental stress. In this way, climate conditions and crop genotype affect the concentration of polyphenols in general, and this interaction with the environment generates reasonable variation in content $[17,18]$. The polyphenols found in the pulp and seeds of Colombian granadilla, as well as its high flavonoid proportion, could explain its effective inhibitory action against inflammatory cytokines, and other biological functions comparable to those of similar types of Passifloras found worldwide.

\section{Weight gain and food consumption}

Treatment with $3.0 \mathrm{~g} / \mathrm{L}$ granadilla polyphenol extract statistically reduced weight gain in Wistar rats despite showing no significant difference in food consumption from the control group. A study using a similar dose (3.2g/L) of polyphenol extracts from green tea reported significant differences in weight gain from week nine [19]. Similarly, other researchers that treated rats with green tea extract at $5.0 \mathrm{~g} / \mathrm{L}$ in drinking water found results consistent with those of the present study [20]. The relationship between polyphenol consumption and weight gain reduction has been explained from multiple physiological perspectives $[21,22]$. Researchers have proven that polyphenols can diminish dietetic lipid absorption; moreover, there is evidence that polyphenols can modulate genes involved in lipid metabolism and hinder formation of adipose tissue $[23,24,20]$.

Considering that being overweight is a determinant factor contributing to metabolic syndrome and has a prevalence of more than $30 \%$ in the USA and China, the 
results of the present work show promising alternative approaches with regard to weight gain control $[25,26,27]$. More studies in humans, including research of highpolyphenol content in regular diets, suggest the possibility of preventive approaches for metabolic syndrome [28].

\section{Inflammatory markers}

A significant decrease in serum TNF- $\alpha$ was observed in overweight rats supplemented with polyphenols. Rats treated with the $3.0 \mathrm{~g} / \mathrm{L}$ dose showed decreased IL-6 levels by about $6 \%$, but this change was not statistically significant. Lu et al. reported that IL-6 levels decreased by the action of green tea polyphenol-supplementation using a $5.0 \mathrm{~g} / \mathrm{L}$ dose in rats fed a high-fat diet [20]. These authors also found a decrease in circulating IL-1 $\beta$, showing that these polyphenols reduce the chronic inflammation generated by high-fat diets. The highest granadilla polyphenol extract dose used in the present investigation was $3.0 \mathrm{~g} / \mathrm{L}$, and supplementation with higher polyphenol contents could suggest statistically significant inhibition of IL-6.

Our results are consistent with those of prior studies reporting decreased IL- 6 and TNF- $\alpha$ following supplementation of rats with $200 \mathrm{mg} / \mathrm{kg} /$ day green tea $[20,30]$. These authors attributed their results to the capacity of polyphenols to protect animals from fatty liver disease, as the cytokines IL- 6 and TNF- $\alpha$ manifest during disease progression and with the appearance of fibrotic lesions [31,32]. Results of the present study concur and are complementary to in vitro assays evaluating the inhibitory action of polyphenols from Passifloras on inflammatory markers tested for transepithelial/endothelial electrical resistance (TEER) [8]. Different phenolic compounds, as identified by UHPLC/MS, showed positive and statically inhibitory action against an inflammatory cocktail containing IL-1 $\beta$, TNF- $\alpha$, IFN- $\gamma$, and pro-inflammatory lipopolysaccharides [8].

Studies with Citrus unshiu supplementation in $\mathrm{db} / \mathrm{db}$ mice resulted in significantly lowered IL- 6 and TNF- $\alpha$, as well as increased adiponectin $[33,34,35]$. The relationship between the effect of adiponectin and the anti-inflammatory activity of polyphenols was reported by Tian et al. (2013) [19], who suggested that these compounds either increase expression of the peroxisome proliferator-activated gamma receptor (PPARy) or inhibit its phosphorylation, stimulating production of adiponectin and regulating production of IL- 6 and TNF- $\alpha$ $[19,36,37]$. Polyphenols are anti-inflammatory agents that inhibit nuclear factor kappa B (NF-kB) and inhibit the induction of expression of pro-inflammatory genes, such as TNF- $\alpha$, IL-1 $\beta$ or IL-8 [36]. Other results in our research suggest that polyphenols in P. ligularis (granadilla) can regulate in vitro specific nuclear mechanisms responsible for low-grade inflammation and weight gain. With respect to a healthy digestive system, the inflammatory markers TNF- $\alpha$ and IL-1 $\beta$ stimulate cell signalling routes that affect membrane integrity and are normally registered as lower transepithelial/endothelial electrical resistance (TEER) values [8]. Positive TEER effects, based on treatment of Caco-2 cells with different doses of polyphenol-extracts from Colombian Passifloras, suggest a direct correlation with the results of in vivo assays in the present work [8].

\section{Conclusion}

The pulpand seeds of Colombian P. ligularis (granadilla) are an important source of polyphenols, with percentages of total flavonoid content reaching around $80 \%$. Polyphenol doses of 2.5 and $3.0 \mathrm{~g} / \mathrm{L}$ have the ability to reduce weight gain in rats. This dietary content of polyphenols suggested as beneficial for human consumption is found in two fresh Colombian granadillas. The evaluated extracts supplemented in the daily diet of Wistar rats were associated with no differences in food consumption, but were statistically correlated with weight gain. Polyphenol treatments inhibited weight gain throughout the study. Results in overweight rats shown in this study illustrate a promising inhibiting action with respect to weight control during consumption of high-calorie diets supplemented with different doses of polyphenol extracts.

Polyphenol extract treatments also statistically decreased serum concentrations of the pro-inflammatory cytokine TNF- $\alpha$ and reduced IL- 6 levels in overweight rats, suggesting an ability to reduce the risk of lowgrade chronic inflammation by acting as inhibitory agents during interleukin activity. Transepithelial/ endothelial electrical resistance in vitro assays in Caco-2 cells corroborate the inhibitory action of polyphenols and flavonoids from Passiflora extracts. More in vivo and human studies would help to evaluate the dietary benefits associated with inclusion of Passifloras, either as fresh fruit or as extracts. Exploration of inhibitory activity against additional cytokines and plasma lipid regulation studies are recommended.

It is also advised to propose further in vivo studies, ultimately culminating in human trials, using $P$. ligularis (granadilla) extracts to evaluate other parameters related to inflammation or macrophage activation in different metabolic pathways. Considering the high presence of 
flavonoids in the total polyphenol content of $P$. ligularis (granadilla) and the positive in vitro and in vivo results indicating inhibition of low-grade inflammatory stages, this study highlights the benefits of the consumption of Passifloras as part of a regular diet.

Acknowledgments: The authors greatly thank Dr. Bradley Bolling of the University of Wisconsin-Madison (USA), Department of Food Science for feedback provided on manuscript drafts and final edition.

Contributions: All authors contributed toward conceptualization and original draft preparation. Methodology, validation, data curation, formal analysis and investigation were carried out by J.A. and J.C. Supervision and administration provided by W.N. and C.G. Funding acquisition, C.G., W.N. and J.C.

Funding: This research was funded by Universidad de Manizales (Colombia) grant 2014/II; COLCIENCIAS Organization (Bogota - Colombia) national doctoral studies scholarship 647/2014; and Universidad de Caldas (Colombia) with the provision of all laboratory facilities.

Conflicts of Interest: Authors state no conflict of interest.

Data Availability Statement: The datasets generated during and analysed during the current study are available from the corresponding author on reasonable request.

\section{References}

1. Furukawa S, Fujita T, Shimabukuro M, Iwaki M, Yamada Y, Nakajima $Y$, et al. Increased oxidative stress in obesity and its impact on metabolic syndrome. J Clin Invest. 2004 Dec;114(12):1752-61.

2. Esser N, Legrand-Poels S, Piette J, Scheen AJ, Paquot N. Inflammation as a link between obesity, metabolic syndrome and type 2 diabetes. Diabetes Res Clin Pract. 2014 Aug;105(2):14150.

3. Bulló M, Casas-Agustench P, Amigó-Correig P, Aranceta J, SalasSalvadó J. Inflammation, obesity and comorbidities: the role of diet. Public Health Nutr. 2007 Oct;10 10A:1164-72.

4. Aherne SA, O’Brien NM. Dietary flavonols: chemistry, food content, and metabolism. Nutrition. 2002 Jan;18(1):75-81.

5. Kuriyama S, Shimazu T, Ohmori K, Kikuchi N, Nakaya N, Nishino $Y$, et al. Green tea consumption and mortality due to cardiovascular disease, cancer, and all causes in Japan: the Ohsaki study. JAMA. 2006 Sep;296(10):1255-65.

6. Sabogal-Palma AC, Chávez-Marín J, Oliveros-Gómez DF, MurilloPerea E, Méndez-Arteaga JJ. Biological characteristics of Passiflora maliformis from South Colombian Massif. Bioagro-. 2016;28(1):3-12.
7. DANE (Departamento Administrativo Nacional de Estadística). Encuesta nacional agropecuaria (ENA); https://www.dane.gov. co/index.php/estadisticas-por-tema/agropecuario/encuestanacional-agropecuaria-ena

8. Carmona-Hernandez JC, Taborda-Ocampo G, Valdez JC, Bolling BW, González-Correa CH. Polyphenol Extracts from Three Colombian Passifloras (Passion Fruits) Prevent InflammationInduced Barrier Dysfunction of Caco-2 Cells. Molecules. 2019 Dec;24(24):4614.

9. Vasco C, Ruales J, Kamal-Eldin A. Total phenolic compounds and antioxidant capacities of major fruits from Ecuador. Food Chem. 2008;111(4):816-23.

10. Pinzón IM, Fischer G, Corredor G. Determinación de los estados de madurez del fruto de la gulupa (Passiflora edulis Sims.). Agron Colomb. 2007;25(1):83-95.

11. Torres A. Caracterización física, química y compuestos bioactivos de pulpa madura de tomate de árbol (Cyphomandra betacea) (Cav.) Sendtn. ALAN. 2012;62(4):381-8.

12. Zapata K, Cortes FB, Rojano BA. Polifenoles y Actividad Antioxidante del Fruto de Guayaba Agria (Psidium araca). Inf Tecnol. 2013;4(5):103-12.

13. Carmona-Hernandez JC, Taborda-Ocampo G, González-Correa $\mathrm{CH}$. Folin-Ciocalteu Reaction Alternatives for Higher Polyphenol Quantitation in Colombian Passion Fruits. Int J Food Sci. 2021 Jan;2021:8871301.

14. Malafaia AB, Nassif PA, Ribas CA, Ariede BL, Sue KN, Cruz MA. Indução de obesidade com sacarose em ratos. Arq Bras Cir Dig. 2013;26 suppl 1:17-21.

15. National Research Council. Guide for the Care and Use of Laboratory Animals, 8th ed. Washington (DC): National Academies Press (US) 2011; http://www.ncbi.nlm.nih.gov/ books/NBK54050/

16. National Research Council. Nutrient Requirements of the Laboratory Rat. National Academies Press (US); https://www. ncbi.nlm.nih.gov/books/NBK231925/

17. Zapata S, Piedrahita AM, Rojano B. Capacidad atrapadora de radicales oxígeno (ORAC) y fenoles totales de frutas y hortalizas de Colombia. Perspect Nutr Hum. 2014;16(1):25-36.

18. Ramos C, Alonso RF. Evaluación de la capacidad antioxidante de productos tradicionales de la Región Junín "Granadilla, Guinda, Habas, Quiwicha, Oca, Quinua, Tuna, Tumbo y Yacon. Universidad Nacional del Centro del Perú. 2011; http:// repositorio.uncp.edu.pe/handle/UNCP/1219

19. Tian C, Ye X, Zhang R, Long J, Ren W, Ding S, et al. Green tea polyphenols reduced fat deposits in high fat-fed rats via erk1/2PPARy-adiponectin pathway. PLoS One. 2013;8(1):e53796.

20. Lu C, Zhu W, Shen CL, Gao W. Green tea polyphenols reduce body weight in rats by modulating obesity-related genes. PLoS One. 2012;7(6):e38332.

21. Shishikura Y, Khokhar S, Murray BS. Effects of tea polyphenols on emulsification of olive oil in a small intestine model system. J Agric Food Chem. 2006 Mar;54(5):1906-13.

22. Raederstorff DG, Schlachter MF, Elste V, Weber P. Effect of EGCG on lipid absorption and plasma lipid levels in rats. J Nutr Biochem. 2003 Jun;14(6):326-32.

23. Wolfram S, Raederstorff D, Wang Y, Teixeira SR, Elste V, Weber P. TEAVIGO (epigallocatechin gallate) supplementation prevents obesity in rodents by reducing adipose tissue mass. Ann Nutr Metab. 2005 Jan-Feb;49(1):54-63. 
24. Chen N, Bezzina R, Hinch E, Lewandowski PA, Cameron-Smith $D$, Mathai ML, et al. Green tea, black tea, and epigallocatechin modify body composition, improve glucose tolerance, and differentially alter metabolic gene expression in rats fed a highfat diet. Nutr Res. 2009 Nov;29(11):784-93.

25. Gepstein V, Weiss R. Obesity as the Main Risk Factor for Metabolic Syndrome in Children. Front Endocrinol (Lausanne). 2019 Aug;10:568.

26. Lent-Schochet $D$, McLaughlin $M$, Ramakrishnan $N$, Jialal I. Exploratory metabolomics of metabolic syndrome: A status report. World J Diabetes. 2019 Jan;10(1):23-36.

27. Wu X, Du R, Hu C, Cheng D, Ma L, Li M, et al. Resting heart rate is associated with metabolic syndrome and predicted 10 -year risk of cardiovascular disease: a cross-sectional study. J Diabetes. 2019 Nov;11(11):884-94.

28. Chiva-Blanch G, Badimon L. Effects of Polyphenol Intake on Metabolic Syndrome: Current Evidences from Human Trials. Oxid Med Cell Longev. 2017;2017:5812401.

29. Chen YK, Cheung C, Reuhl KR, Liu AB, Lee MJ, Lu YP, et al. Effects of green tea polyphenol (-)-epigallocatechin-3-gallate on newly developed high-fat/Western-style diet-induced obesity and metabolic syndrome in mice. J Agric Food Chem. 2011 Nov;59(21):11862-71.

30. Tan Y, Kim J, Cheng J, Ong M, Lao WG, Jin XL, et al. Green tea polyphenols ameliorate non-alcoholic fatty liver disease through upregulating AMPK activation in high fat fed Zucker fatty rats. World J Gastroenterol. 2017 Jun;23(21):3805-14.

31. Kishimoto T. IL-6: from its discovery to clinical applications. Int Immunol. 2010 May;22(5):347-52.

32. Lesmana CR, Hasan I, Budihusodo U, Gani RA, Krisnuhoni E, Akbar N, et al. Diagnostic value of a group of biochemical markers of liver fibrosis in patients with non-alcoholic steatohepatitis. J Dig Dis. 2009 Aug;10(3):201-6.

33. Park HJ, Jung UJ, Cho SJ, Jung HK, Shim S, Choi MS. Citrus unshiu peel extract ameliorates hyperglycemia and hepatic steatosis by altering inflammation and hepatic glucose- and lipid-regulating enzymes in db/db mice. J Nutr Biochem. 2013 Feb;24(2):419-27.

34. Romier B, Van De Walle J, During A, Larondelle Y, Schneider Y). Modulation of signalling nuclear factor-kappaB activation pathway by polyphenols in human intestinal Caco-2 cells. Br J Nutr. 2008 Sep;100(3):542-51.

35. Folco EJ, Rocha VZ, López-Ilasaca M, Libby P. Adiponectin inhibits pro-inflammatory signaling in human macrophages independent of interleukin-10. J Biol Chem. 2009 Sep;284(38):25569-75.

36. Kusminski CM, Scherer PE. The road from discovery to clinic: adiponectin as a biomarker of metabolic status. Clin Pharmacol Ther. 2009 Dec;86(6):592-5. 